\title{
Analisis Nilai Tambah Pengolahan Ubi Ungu di PO. Imo Syrup Denpasar
}

\section{REYDELT SAPLORI JOI TAMSAR, I WAYAN BUDIASA, I GAA LIES ANGGRENI}

PS Agribisnis Fakultas Pertanian Universitas Udayana

Jl. PB. Sudirman Denpasar 80232 Bali

Email: reydelt.tamsar@gmail.com

wba.agr@unud.ac.id

\section{Abstract \\ Analysis of the Value Additional Processing Of Purple Sweet Potato in PO. Imo Syrup Denpasar.}

PO. Imo Syrup Denpasar is the business processing a purple sweet potato into syrup and juice so as to be durable and provide value added of a product. The purpose of this study is to determine the size of value added of purple sweet potato as the raw materials of syrup and juice and to calculate provit level obtained the company. The research analysis used of the value added Hayami and BEP method with cycles once process production. The research results showed that $10 \mathrm{~kg}$ purple sweet potato become $18,75 \mathrm{~L}$ syrup and value added is $\mathrm{Rp} 59.660 / \mathrm{L}$ syrup, processing $10 \mathrm{~kg}$ purple potato became $15 \mathrm{~L}$ juice and value added $\mathrm{Rp} 72.500 / \mathrm{L}$ juice. Advantages of gained for one of a production peocess is Rp.52.760 /L Syrup and foe juice is Rp 65.600/L. This effort is also supported by the acquiremwnt on syrup worth Rp.10.416.666 or in break event condition can be obtained by selling as much syrup $221,63 / \mathrm{L}$ with selling price Rp.6.693/L. At the minimum sale of juice or in breakeven points Rp.1.736.111 or to produce a much 126,08 L with selling price Rp.980,85/L. Financially PO. Imo Syrup Denpasar can be said profitable. The sugestion that can be given to company is do the promotion by social media. so that the people knows about benefit of and an existance of juice and syrup purple sweet potato.

Keywords: value added, purple sweet potato

\section{Pendahuluan}

\subsection{Latar Belakang}

Sektor pertanian merupakan salah satu sektor yang sangat berperan penting dalam memajukan kesejahteraan masyarakat dan juga dalam mendukung perekonomian Indonesia. Menurut Soekartawi (2002) kebijakan pembangunan pertanian di Indonesia senantiasa didasarkan pada amanat yang tertulis dalam Garis-Garis Besar Haluan Negara. Ubi jalar (Ipomoea batatas L.) merupakan salah satu komoditas pertanian yang dapat dibudidayakan oleh penduduk yang tinggal di daerah tropis. Indonesia merupakan daerah tropis sehingga penduduk daerah dataran rendah sampai dataran tinggi dapat membudidayakannya. Indonesia merupakan penghasil ubi jalar terbesar ke tiga di dunia 
setelah RRC dan Vietnam. Menurut Hayami (1990) ada dua cara menghitung nilai tambah yaitu: (1). nilai untuk pengolahan dan (2) nilai tambah untuk pemasaran.

Pengertian agroindustri secara eksplisit yaitu perusahaan yang memproses bahan nabati (yang berasal dari tanaman) dan hewani (yang berasal dari hewan). Proses yang digunakan mencakup pengubahan dan pengawetan melakukan perlakuan fisik atau kimiawi, penyimpanan, pengemasan, dan distribusi (Austin, 1981).Faktor-faktor yang mempengaruhi nilai tambah untuk pengolahan dapat dikelompokkan menjadi dua yaitu faktor teknis dan faktor pasar. Faktor teknis mempengaruhi faktor produksi jumlah bahan baku dan tenaga kerja. Faktor pasar mempengaruhi harga output, upah tenaga kerja dan bahan baku serta nilai input lain. Pengembangan struktur agribisnis nasional diarahkan pada dua sasaran pokok utama yaitu: pertama, masalah mengembangkan struktur agribisnis yang terintegrasi secara vertikal mengikuti suatu aliran produk sehingga subsektor agribisnis hulu, subsektor agribisnis primer dan subsektor agribisnis hilir berada dalam suatu keputusan manajemen. Kedua mengembangkan organisasi bisnis atau ekonomi petani agar dapat merebut nilai tambah yang ada pada subsistem agribisnis hulu dan subsektor agribisnis hilir (Bungaran 2001).

PO. Imo Syrup Denpasar adalah perusahaan yang mampu melihat peluang usaha syrup dan jus sehingga mampu meningkatkan nilai tambah (value added) dari ubi ungu, dan sekarang hasilnya dapat dinikmati oleh masyarakat dalam maupun luar kota. terutama saus, dan pakan ternak. Ubi jalar merupakan makanan yang tergolong memiliki indeks glikemik 54 yang tergolong rendah dimana artinya bahwa karbohidratnya tidak mudah diubah menjadi gula sehingga sangat baik untuk dikonsumsi penderita diabetes (Kunia, 2009). Khususnya untuk saat ini makanan yang banyak digemari dan dicari masyarakat adalah makanan yang baik untuk kesehatan, disamping memang bahan bakunya dari ubi ungu yang punya banyak khasiat bagi tubuh. Selain dari industri ini dapat membuka lapangan pekerjaan, dapat menampung hasil ubi jalar yang dibudidayakan oleh petani, namun mampu juga menghasilkan produk baru yang memiliki nilai ekonomis yang lebih tinggi setelah adanya proses pengolahan lanjutan, karena telah dikeluarkan tambahan biaya untuk pengolahan maka nantinya akan dapat menciptakan harga yang baru atau nilai tambah yang tentunya lebih tinggi dan juga keuntungan yang lebih besar dibandingkan dengan tanpa adanya pengolahan lanjutan. Menurut Winarto dkk (1987), arah pembangunan pertanian di Indonesia di masa mendatang dilakukan dengan cara sebagai berikut: pertama untuk meningkatkan nilai tambah komoditi pertanian, maka diarahkan adanya upaya mendirikan industri pertanian yang dekat dengan daerah sentral produksi. Upaya ini sekaligus dapat menyerap tenaga kerja di pedesaan. Kedua untuk mendapatkan pendapatan usaha tani maka program teknologi pra dan pasca panen perlu disempurnakan dan ditingkatkan.

\subsection{Tujuan Penelitian}

Tujuan dari penelitian ini adalah untuk mengetahui tiga hal pokok sebagai berikut:

1. Mengetahui besarnya nilai tambah ubi jalar ungu sebagai bahan olahan pada PO. Imo Syrup Denpasar.

2. Menghitung tingkat keuntungan yang diterima oleh PO. Imo Syrup Denpasar.

3. Mengetahui Break Event Point pada PO. Imo Syrup Denpasar. 


\section{Metodologi Penelitian}

\subsection{Lokasi dan Waktu Penelitian}

Penelitian ini dilakukan pada PO. Imo Syrup, Jln Soka Gg Kertapura IV No.16 Denpasar, Bali. Penelitian ini dilakukan pada bulan Februari sampai Juni 2015.

\subsection{Responden Penelitian}

Penentuan responden penelitian ini dilakukan dengan metode purposive sampling yaitu pemilihan informan kunci secara sengaja berdasarkan tugas dan tanggung jawab pada perusahaan serta dianggap mampu memberikan keterangan yang diperlukan yaitu sebanyak tiga orang terbagi atas satu orang pemilik perusahaan (owner), satu orang karyawan dibagian produksi, dan satu orang karyawan yang bertanggung jawab dalam pengurusan pemasaran sekaligus merangkap dibagian administrasi.

\subsection{Jenis dan Sumber Data, Variabel Penelitian, dan Metode Analisis}

Jenis data yang dipergunakan dalam penelitian ini adalah berupa data kuantitatif dan kualitatif. Penelitian ini menggunakan data yang berasal dari dua sumber yaitu data primer dan data sekunder. Data primer adalah data yang diperoleh secara langsung dari sumbernya, yaitu data dari perusahaan. Data sekunder adalah data yang diperoleh secara tidak sengaja tetapi masih berhubungan dengan objek penelitian. Variabel yang diteliti adalah nilai tambah pada produk olahan ubi ungu menjadi jus dan syrup yang dianalisis dengan Metode Hayami, keuntungan usaha olahan ubi ungu, dan Break Event Point (BEP). Variabel ini akan dianalisis melalui metode analisis kuantitatif dan metode analisis kualitatif. Untuk memaksimalkan laba perusahaan harus mengerti tentang salah satu prinsip dasar dalam ekonomi mikro yaitu biaya marginal atau penerimaan marginal. (Firdaus, 2012).

\subsubsection{Analisis nilai tambah}

Menghitung besarnya nilai tambah dan keuntungan pada olahan ubi ungu dilakukan dengan menggunakan analisis nilai tambah dengan metode Hayami (Sudiyono, 2002). Hasil perhitungan akan dihasilkan perkiraan nilai tambah (Rp/liter) dan keuntungan (Rp/liter) untuk produk olahan jus dan syrup. Nilai tambah (value added) adalah pengukuran performance entitas ekonomi yang memiliki sejarah panjang pada aplikasinya dalam ilmu ekonomi. Nilai tambah merupakan konsep utama dalam mengukur income. ( Mulawarman, 2008)

\subsubsection{Sumbangan input lain}

Proses pengolahan ubi ungu memerlukan sumbangan input lain yang diperhitungkan meliputi bahan penolong, bahan bakar, dan bahan pengemas. Besarnya sumbangan input lain dipengaruhi oleh banyaknya jenis bahan penunjang. Lebih jelasnya format perhitungan sumbangan input lain adalah sebagai berikut:

$$
\text { Sumbangan input lain }=\frac{\text { total sumbangan input lain }(\mathrm{Rp})}{\text { jumlah bahan baku }(\mathrm{kg})}
$$




\subsubsection{Perhitungan break event point (BEP)}

BEP (Break Event Point) merupakan analisis yang menunjukkan hubungan antara investasi dan volume produksi atau penjualan untuk mendapatkan suatu tingkat profitabilitas (Muslich,2000).

Perhitungan BEP atas dasar unit produksi dapat dilakukan dengan menggunakan rumus:

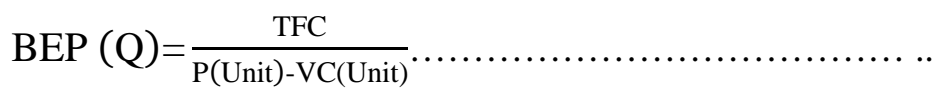

Perhitungan BEP atas dasar unit rupiah dapat dilakukan dengan menggunakan rumus:

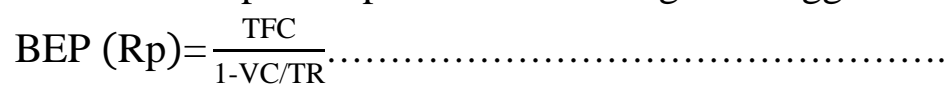

\section{Hasil dan Pembahasan}

\subsection{Analisis Nilai Tambah Produk Olahan Ubi Jalar Ungu}

Analisis nilai tambah digunakan untuk mengetahui besarnya nilai tambah (value added) yang terdapat pada ubi jalar ungu yang diolah menjadi syrup dan jus. Adapun dasar perhitungan nilai tambah olahan ubi jalar ungu adalah harga rata-rata bahan baku untuk satu kali proses produksi. Harga pembelian bahan baku ubi ungu per kilogram adalah sebesar Rp 3.000,00 per kg yang langsung diperoleh dari petani di desa Tua, Kecamatan Marga Kabupaten Tabanan dengan kualitas ukuran umbi minimal 5 cm.Besarnya analisis nilai tambah pada olahan ubi jalar ungu untuk satu kali proses produksi olahan pada PO. Imo Syrup dapat dilihat pada Tabel 1

Proses pengolahan ubi jalar ungu pada pembuatan syrup dan jus sama-sama membutuhkan jumlah bahan baku yang sama yaitu $10 \mathrm{~kg}$ untuk sekali proses produksi yang nantinya dapat menghasilkan 18,75 liter syrup dan sebanyak 15 liter untuk jus. untuk satu kali proses produksi olahan dari ubi jalar ungu yang memberikan nilai tambah yang lebih tinggi ialah jus yaitu sebesar Rp 72.500,00 / kg dibandingkan dengan syrup yang hanya $\mathrm{Rp} 59.660,00 / \mathrm{kg}$ dengan penggunaan bahan baku sama-sama $10 \mathrm{~kg}$. Harga output dari setiap produk olahan ubi ungu yaitu untuk syrup Rp 48.000,00 /liter dan untuk jus Rp 67.000,00 /liter.

Faktor konversi merupakan hasil bagi antara hasil produksi/output dengan jumlah bahan baku/input yang digunakan, besarnya faktor konversi pada syrup adalah sebesar 1,87 yang berarti bahwa $1 \mathrm{~kg}$ bahan baku dapat dihasilkan 1,87 liter syrup, sedangkan faktor konversi pada jus yaitu sebesar 1.5 yang berarti bahwa $1 \mathrm{~kg}$ bahan baku akan menghasilkan 1,5 liter jus. Koefisien tenaga kerja merupakan hasil bagi antara tenaga kerja dengan jumlah bahan baku yang dipergunakan dalam proses produksi. Besarnya nilai koefisien tenaga kerja pada hasil olahan syrup dan jus sebesar 0,115 hal ini memiliki nilai yang sama karena jumlah tenaga kerja dan waktu yang dibutuhkan untuk mengolah kedua produk tersebut sama. Pendapatan tenaga kerja langsung pada pengolahan syrup dan jus adalah sebesar Rp 6.900,00 untuk satu kali proses produksi, keduanya memiliki nilai yang sama karena jumlah tenaga kerja dan waktu yang dibutuhkan untuk mengolah syrup dan jus adalah sama. Sumbangan input 
lain yang dibutuhkan untuk satu kali proses produksi pada syrup yaitu sebesar Rp $27.100,00 / \mathrm{kg}$ bahan baku dan sebesar Rp 25.000,00/ kg bahan baku untuk pembuatan jus.

Hasil analisis juga dapat diketahui bahwa keuntungan tertinggi yang diperoleh ialah dari pengolahan jus yaitu sebesar Rp 65.600,00 dengan tingkat keuntungan sebesar $65,27 \%$, sedangkan dari hasil pengolahan syrup hanya sebesar Rp 52.760,00 dengan tingkat keuntungan sebesar 58,77\%.

Hasil analisis nilai tambah ini juga menunjukkan margin dari bahan baku ubi jalar ungu menjadi hasil olahan syrup dan jus yang didistribusikan kepada pendapatan tenaga kerja, sumbangan input lain dan keutungan perusahaan. Margin tertinggi terdapat pada jus yaitu sebesar Rp 97.500,00 yang didistribusikan untuk masing-masing faktor yaitu pendapatan tenaga kerja langsung sebesar 7,07 \%, sumbangan input lain 25,64\% dan keuntungan perusahaan $67,28 \%$. Analisis nilai tambah juga berguna untuk mengetahui berapa tambahan nilai yang terdapat pada satu satuan output yang dihasilkan (nilai tambah produk), nilai tambah ini merupakan keuntungan kotor sebelum dikurangi biaya tetap (Purba, 1986).

Tabel 1.

Analisis Nilai Tambah pada Produk Olahan Ubi Ungu di PO Imo Syrup

\begin{tabular}{rlcc}
\hline No & Variabel & \multicolumn{2}{c}{ Nilai } \\
\hline & I. Output, Input dan Harga & Syrup & Jus \\
\hline 1 & Output (liter/ proses) & 18,75 & 15 \\
2 & Input bahan baku (kg/ proses) & 10 & 10 \\
3 & Input tenaga kerja (HOK/ proses) & 1,15 & 1,15 \\
4 & Faktor konversi (liter/kg) & 1,87 & 1.5 \\
5 & Koefisien tenaga kerja (HOK/ kg) & 0,115 & 0,115 \\
6 & Harga output(Rp/ liter) & 48.000 & 67.000 \\
7 & Tingkat upah (Rp/ HOK) & 60.000 & 60.000 \\
\hline & II. Penerimaan, Nilai Tambah dan Keuntungan & & \\
\hline 8 & Harga bahan baku (Rp/ kg bahan baku) & 3.000 & 3.000 \\
9 & Sumbangan input lain (Rp/ kg bahan baku)* & 27.100 & 25.000 \\
10 & Nilai output (Rp/ liter ) & 89.760 & 100.500 \\
11 & a. Nilai tambah (Rp/ kg bahan baku) & 59.660 & 72.500 \\
& b. Ratio nilai tambah (\%) & 66.46 & 72.13 \\
12 & a. Imbalan tenaga kerja & 6.900 & 6.900 \\
& b. Persentase kontribusi tenaga kerja (\%) & 7.68 & 9.51 \\
13 & a. Keuntungan pengolah & 52760 & 65600 \\
& b. Tingkat keuntungan (\%) & 58.77 & 65.27 \\
\hline
\end{tabular}

III. Balas Jasa Pemilik Faktor-Falktor Produksi 


\begin{tabular}{lcr}
\hline 14 Marjinal (Rp/kg) & 86.760 & 97.500 \\
a. Pendapatan tenaga kerja langsung (\%) & 7,95 & 7,07 \\
b. Sumbangan input lain (\%) & 31,23 & 25,64 \\
c. Keuntungan pemilik perusahaan $(\%)$ & 60,81 & 67,28 \\
\hline
\end{tabular}

Sumber : Data Primer, 2015.

\subsection{Keuntungan Usaha Olahan Ubi Ungu PO. Imo Syrup}

Berdasarkan hasil perhitungan dengan metode Hayami, keuntungan diperoleh dari besar nilai tambah dikurangi pendapatan tenaga kerja langsung. Besar keuntungan yang diterima perusahaan per satu kali proses produksi dapat dilihat pada Tabel 2 di bawah ini.

Tabel 2.

Keuntungan Produk Olahan Ubi Ungu per Proses Produksi

\begin{tabular}{cc}
\hline Jenis Produk & Keuntungan (Rp) \\
\hline Syrup & 52.760 \\
Jus & 65.600 \\
\hline
\end{tabular}

Tabel 2 diatas, maka dapat dilihat bahwa keuntungan produk jus lebih tinggi yaitu sebesar Rp 65.600,00 / kg dibandingkan dengan syrup yang hanya sebesar Rp $52.760,00 / \mathrm{kg}$. Besar keuntungan diperoleh dari besar nilai tambah dikurangi dengan pendapatan tenaga kerja langsung. Tingginya keuntungan jus disebabkan karena besar nilai tambah pada jus sangat tinggi yaitu sebesar Rp 72.500,00/ kg, dibandingkan dengan nilai tambah pada syrup yang hanya sebesar Rp 59.660,00/ kg.

\subsection{Break Even Point (BEP) pada PO Imo Syrup}

BEP dinyatakan dengan satuan rupiah ( $\mathrm{Rp}$ ) dan satuan penjualan (liter), yang menunjukkan nilai dan jumlah penjualan jus dan syrup dimana perusahaan tidak mengalami kerugian dan tidak mengalami keuntungan.

Tabel 3.

Nilai BEP Usaha Pengolahan Ubi Ungu pada PO Imo Syrup, Tahun 2015

\begin{tabular}{lcc}
\hline \multicolumn{1}{c}{ Uraian } & \multicolumn{2}{c}{ Produk olahan } \\
\hline Biaya tetap (Rp) & Syrup & Jus \\
Biaya tidak tetap (Rp) & 1.250 .000 & 1.250 .000 \\
Volume produksi (liter) & 65.923 .000 & 33.770 .000 \\
Harga jual (Rp/liter) & $1.556,25$ & 1.770 \\
Penerimaan (Rp) & 48.000 & 67.000 \\
BEP volume produksi (liter) & 74.700 .000 & 118.590 .000 \\
BEP penerimaan (Rp) & 221,63 & 126,08 \\
BEP Rupiah/liter (Rp/liter) & 10.416 .666 & 1.736 .111 \\
& $6.693,44$ & 980,85 \\
\hline
\end{tabular}


PO Imo Syrup dalam pengolahan syrup berada pada kondisi impas dalam unit saat perusahaan hanya memproduksi 221,63 liter syrup dengan BEP penerimaan sebesar Rp 10.416.666,00. Sedangkan pada olahan jus berada pada kondisi titik impas dalam unit pada saat perusahaan hanya memproduksi 126,08 liter jus dengan BEP penerimaan Rp 1.736.111,00.

\section{Kesimpulan dan Saran}

\subsection{Kesimpulan}

Dari hasil pembahasan yang telah dilakukan maka dapat disimpulkan bahwa:

1. Nilai tambah yang diperoleh dari pengolahan ubi ungu menjadi syrup yaitu sebesar Rp 59.660,00/kg dan keuntungan yang diperoleh sebesar Rp 52.760,00/kg bahan baku. Nilai tambah yang diperoleh pada pengolahan ubi ungu menjadi jus yaitu sebesar Rp $72.500,00 / \mathrm{kg}$ dan keuntungan yang diperoleh yaitu Rp $65.600,00 / \mathrm{kg}$

2. Keuntungan yang tertinggi per proses produksi terdapat pada jus yaitu sebesar Rp 65.600,00/Kg bahan baku, sedangkan pada Syrup sebesar Rp 52.760,00/kg bahan baku. Total keuntungan yang diperoleh perusahaan untuk kedua produk olahan dari $20 \mathrm{~kg}$ bahan baku sebesar Rp 1.183.600,00 per satu kali produksi.

Hal ini didukung dengan perolehan nilai BEP tingkat penjualan minimum sebagai berikut:

a. Tingkat penerimaan minimum pada syrup adalah senilai Rp 10.416.666 atau kondisi impas itu dapat diperoleh dengan memproduksi sebanyak 221,63 liter dengan harga jual per unit Rp 6.693,44/liter

b. Pada pengolahan jus diperoleh kondisi impas dengan penerimaan minimum sebesar Rp 1.736.111,11 atau dengan memproduksi sebanyak 126,08 liter dengan harga jual per unit Rp 980,85/liter.

\subsection{Saran}

Berdasarkan hasil pembahasan dan kesimpulan di atas, maka dapat disarankan kepada PO. Imo Syrup sebagai berikut:

1. Diharapkan agar dapat menciptakan dalam bentuk olahan lain yang lebih diminati masyarakat karena usaha ini mampu membuka lapangan pekerjaan demikian juga dapat membantu petani dalam pembelian bahan baku dengan harga yang lebih tinggi.

2. Pada pihak usaha agar mendistribusikan produk olahan salak secara luas untuk menambah daerah pemasaran serta menggunakan media sosial sebagai wadah pengenalan akan produk hasil olahan. 


\section{Ucapan Terima Kasih}

Terimakasih kepada seluruh tenaga kerja dan pemilik PO. Imo Syrup Denpasar yang telah membantu sehingga memudahkan penelitian ini dalam pengumpulan data serta kepada semua pihak yang membatu kelancaran penelitian ini.

\section{Daftar Pustaka}

Austin, J.E. 1981. Agroindustrial Project Analysis. The John Hopkins University Prss. London

Badan Pusat Statistik.2012.Produksi Tanaman Ubi Jalar. www.bps.co.id. Diunduh pada tanggal 5 maret 2015.

Djamin, Z. 1993. Perencanaan dan Analisis Proyek. Lembaga penerbit Fakultas Ekonomi Universitas Indonesia, Jakarta.

Firdaus, M. 2012. Manajemen Agribisnis. Jakarta: Bumi Aksara

Hayami, Y. et.all. 1990. Agriculture Marketing and Processing in Upload Java: A Perspektive from a Sunda Village. CGPRT Bogor. Ch.6. PP.43-47.

Kunia, K.2009. Yuk Makan Kudapan Sehat. Pusat Penelitian Bioteknologi Institut Teknologi Bandung, Bandung

Mulawarman, A.D. 2008. Eksistensi Laporan Nilai Tambah Syari'ah Berbasis Rezeki. Simposium Nasional Akuntansi 11. Pontianak

Muslich, Mohamad. 2000. Manajemen Keuangan Modern, Analisis, Perencanaan dan Kebijakan. PT Bumi Aksara : Jakarta

Purba, R. 1986. Manajemen Manunggal bagi Wiraswasta. Pustaka Dian. Jakarta.

Saragih, B., 2001. Agribisnis Paradigma Baru Pembangunan Ekonomi Berbasis Pertanian (terbitan kedua). Penerbit Yayasan Mulia Persada Indonesia dan PT Suveyor Indonesia bekerjasama dengan Pusat Pembangunan IPB dan Unit for Sosial and Economic Studies and Evaluation (USESE) foundation. Bogor.

Soekartawi. 2002. Prinsip Dasar Ekonomi Pertanian. Jakarta: Raja Grafindo Persada.

Winarto, A., H. Subagio, dan K.H. Hendroatmodjo. 1994. Potensi dan Tantangan Usaha Meningkatkan Ubi jalar: Tinjauan dari Kecenderungan Sikap dan Perilaku Konsumen. Risalah Seminar Penerapan Teknologi Produksi dan Pasca Panen Ubi jalar Mendukung Agroindustri. Balai Penelitian Tanaman Pangan, Pusat Penelitian dan Pengembangan Tanaman Pangan, Badan Penelitian dan Pengembangan Pertanian, Malang. 